Conclusions: The novel FOI RA synovitis scoring system showed high reliability and moderate to good responsiveness in the wrist and hand. Future studies should focus on assessing the sensitivity and specificity of the FOI synovitis score with ultrasound and magnetic resonance imaging as gold standard.

Disclosure of Interest: None declared

DOI: 10.1136/annrheumdis-2017-eular.4633

\section{AB1014 SAFETY OF OUTPATIENT PERCUTANEOUS NATIVE RENAL BIOPSY IN PATIENTS WITH SYSTEMIC AUTOIMMUNE DISEASES: RESULTS FROM A MONOCENTRIC COHORT}

D. Roccatello, S. Sciascia, D. Rossi, C. Naretto, M. Bazzan, L. Solfietti, M. Radin, S. Baldovino, E. Menegatti. Department of Rare and Immunologic Diseases, G. Bosco Hospital and University of Turin, TOrino, Italy

Background: Renal involvement is common in patients with systemic autoimmune conditions, mainly systemic lupus erythematosus (SLE) and vasculitis, including cryoglobulinemia. Despite the advances in percutaneous kidney biopsy (PKB) techniques and overall improved safety of the procedure, clinically significant bleeding complications do occur.

Objectives: to investigate the safety of performing percutaneous native kidney biopsy (PKB) as an outpatient procedure (implying an observation period of $6 \mathrm{hrs}$ ) compared to the traditional inpatient policy in patients with systemic autoimmune conditions.

Methods: Group I, in whom PKB was performed in the outpatient department (2012-2016) and followed by 6 hours' observation period and then by regular outpatient visits and group II, in whom PKB was performed and followed by at least 1-day hospital admission. Group II included retrospectively retrieved patients who underwent PKB in our Institution between January 2000 and November 2012 as in patient procedure. All biopsies were performed by a single nephrologist following a structured protocol.

Results: A total of 81 biopsies (group I and group II) were included in this study, 44 $(54 \%)$ of patients were female and the mean age was $49.9 \pm 17.6$ years. Twenty-six per cent of biopsies were performed for the diagnostic workup of nephrotic range proteinuria, $21 \%$ for rapidly progressive renal insufficiency, and the remaining $53 \%$ for non-nephrotic proteinuria and/or hematuria. No patient suffered for a major complication and only $3(3.7 \%)$ patients (one with cryoglobulinemic vasculitis and 2 with ANCA associated vasculits) developed a minor complication, including gross hematuria in one case and sub-capsular perinephric hematoma on sonography not requiring intervention in 2 patients

Conclusions: The lack of major complications and the very limited rate of minor bleeding support that outpatient biopsy could be a valuable, safe, and perhaps cost-effective method of obtaining diagnostic renal tissue in the majority of patients with systemic autoimmune diseases.

Disclosure of Interest: None declared

DOI: 10.1136/annrheumdis-2017-eular.2162

\section{AB1015 AUTOMATED SQUEEZE TEST (GAENSLEN'S COMPRESSION MANEUVER) IN RHEUMATOID ARTHRITIS PATIENTS. EXPLORATORY STUDY}

D. Vega-Morales, J.A. Esquivel-Valerio, A.C. Arana-Guajardo,

M.A. Garza-Elizondo. Rheumatology Service, Hospital Universitario Dr. José Eleuterio González, Monterrey, Mexico

Background: The squeeze test (a.k.a Gaenslen's Compression Maneuver) consists on the compression of the metacarpal-phalangeal (MCP) joints to elicit pain in a patient with active synovitis. The squeeze test has three main purposes: Screening of inflammatory arthritis, as a predictor of rheumatoid arthritis in arthralgia patients, and as a quick and practical evaluation of the presence/absence of synovitis in patients already diagnosed with RA. The force and the way to perform the squeeze test had been evaluated in rheumatologists on a biomechanical device, with conflicting results. We developed a biomechanical device to perform the squeeze test.

Objectives: Our aim is to determine the force whether the automated squeeze test discriminate patients with active RA from inactive ones. And the force that differentiates a healthy patient from a RA patient.

Methods: Observational study in RA (ACR/EULAR 2010) patients and healthy persons. We perform 3-squeeze test on the device in the MCP joints and record the force enough to elicit pain. And then compare them with the joint counts by the clinician

Results: Two hundred MCP joints from 50 hands were tested. From 25 RA patients with a mean age of 54.6 years (SD 11.22), with a mean disease latency of 1.2 years (SD 2.7). The total swollen joint count was 16 (7 right joints +9 left joints) and 70 total tender joint count (30 right joints and 40 left joints). The median of force that caused pain in the RA patient's right hand was $3.07 \mathrm{~kg}$ (IQR 2.4) and the left hand was $2.78 \mathrm{~kg}$ (IQR 3.8). The cut-off for the force to detect a tender right hand joint was 1,020 grams with a sensitivity of $100 \%$ and specificity of $10 \%$; for a swollen right hand joint was 1,400 with a sensitivity of $100 \%$ and specificity of $28.6 \%$. For a tender left hand joint was 1620 grams with a sensitivity $70 \%$ and specificity of $6.7 \%$; and for a swollen left joint was 1990 grams with a sensitivity of $100 \%$ and specificity of $27.3 \%$.

In the second phase, $560 \mathrm{MCP}$ joints of 140 hands from 70 healthy volunteers were compressed. The median force to elicit pain in the right hand was $4.2 \mathrm{~kg}$ (IQR 9.5) vs. $3.07 \mathrm{~kg}$ (IQR 8.7) from RA patients $(\mathrm{p}=0.003)$. And for left hand 4.6 $\mathrm{kg}$ (IQR 9.7) vs. $2.78 \mathrm{~kg}$ (IQR 9.2) from RA ( $\mathrm{p}=0.014)$.

Conclusions: It is necessary to continue the exploration of the maneuver in different clinical settings. Validate the strength in patients with different arthropathies, activity levels and different clinical stages (screening, activity, prediction) and also with imaging methods for evidence of inflammation (US, MRI) Disclosure of Interest: None declared

DOI: 10.1136/annrheumdis-2017-eular.3318

\section{AB1016 ANTI-DFS70, A TOOL IN USUAL CLINICAL PRACTICE: A CASE SERIES}

D. Ybáñez-García ${ }^{1}$, E. Valls-Pascual ${ }^{1}$, C. Vergara-Dangond ${ }^{1}$,

M. Aguilar-Zamora ${ }^{1}$, L. Montolio-Chiva ${ }^{1}$, Á. Martínez-Ferrer $^{1}$

J.M. López-Ortega ${ }^{2}$, J.J. Alegre-Sancho ${ }^{1}{ }^{1}{ }^{1}$ Rheumatology; ${ }^{2}$ Clinical Analysis

Laboratory Service, Hospital Universitario Dr. Peset, Valencia, Spain

Background: The presence of anti-nuclear antibodies (ANA) has been considered a characteristic of systemic autoimmune diseases (SAD). Patients are frequently referred for study because they have ANA and are followed because of the possibility to develop SAD. Approximately, $20 \%$ of healthy individuals with ANA detected by indirect immunofluorescence $(\mathrm{IFI})$, especially at low titers, have a dense, fine speckled pattern (DFS) that frequently corresponds to the presence of anti-DFS70 antibodies. The importance of this antibody is due to its low prevalence in subjects with ASD $(<1 \%)$ compared to its presence in $33.1 \%$ of healthy subjects with ANA.

Objectives: To describe the usefulness of Anti-DFS70 in a series of patients presenting ANA.

Methods: We collected prospectively throughout the year 2016 all the patients referred to a tertiary hospital for ANA study and in whom the presence of anti-DFS70 antibodies was confirmed. All patients underwent a thorough medical history, physical examination, and relevant follow-up tests were performed according to the clinical presentation. The IFI was performed in a Menarini Zenit-Up/GSight system, as well as ANA screening in Hep-2000 (Fluorescent IgG ANA-Ro Test System-immunoconcepts) and the detection of anti-DFS70 antibodies by immunoblot (ANA + DFS70 Dot Blot-Alphadia).

Results: We collected in a period of 12 months a total of 7 patients with anti-DFS70 antibodies. Most of them (6/7) were referred because of non-specific symptoms such as arthralgia, fatigue, thrush, edema, ... and the presence of ANA. The findings are detailed in Table 1.

\begin{tabular}{|c|c|c|c|c|c|c|c|}
\hline Case & 1 & 2 & 3 & 4 & 5 & 6 & 7 \\
\hline Symptoms & $\begin{array}{l}\text { Polyarthralgias Arthritis } \\
\text { 4th interphalangeal joint }\end{array}$ & $\begin{array}{c}\text { General pain } \\
\text { Dry eye and dry mouth }\end{array}$ & $\begin{array}{c}\text { Polyarthralgias } \\
\text { Back pain } \\
\text { Inflammatory markers + }\end{array}$ & $\begin{array}{l}\text { Arthromyalgias } \\
\text { Fatigue } \\
\text { Fever } \\
\text { Anti-TNF-a }\end{array}$ & $\begin{array}{c}\text { Polyarthralgias } \\
\text { Back pain } \\
\text { Fatigue, oral aphthosis }\end{array}$ & $\begin{array}{l}\text { Hand pain and deformity } \\
\text { of 2nd PIPs }\end{array}$ & Left foot edema \\
\hline Gender & \% & $q$ & \% & $\sigma^{\prime}$ & ९ & \% & ९ \\
\hline Age & 45 & 47 & 37 & 48 & 39 & $\stackrel{+}{56}$ & $\stackrel{+}{55}$ \\
\hline Hemogram/Renal/liver function & $\mathrm{N}$ & $\mathrm{N}$ & $\mathrm{N}$ & $\mathrm{N}$ & $\mathrm{N}$ & $\mathrm{N}$ & $\mathrm{N}$ \\
\hline RF/ACPA & $(-)$ & $(-)$ & $(-)$ & $(-)$ & $(-)$ & $(-)$ & $(-)$ \\
\hline ANA (IFI)/ENAs & $+1 / 160 /-$ & $+1 / 160 /-$ & $+1 / 320 /-$ & $+1 / 160 /-$ & $+1 / 160 /-$ & $+1 / 320 /-$ & $+1 / 80 /-$ \\
\hline $\mathrm{C} 3, \mathrm{C} 4$ & NP & $\mathrm{N}$ & NP & NP & NP & NP & NP \\
\hline Schirmer/Ss & NP & $\mathrm{N}$ & NP & $\mathrm{NP}$ & NP & NP & NP \\
\hline CRP/ESR & $\mathrm{N}$ & $\mathrm{N}$ & $21 / 17$ & $N$ & $\mathrm{~N}$ & $\mathrm{~N}$ & $\mathrm{~N}$ \\
\hline Comorbidities & Type 2 DM & Graves Basedow & Hand angioedema & PsA & Graves Basedow & Dyslipidemia & No \\
\hline $\mathrm{RX} / \mathrm{MRI}$ & CPPD & $\begin{array}{l}\text { Degeneration of left } \\
\text { TMC and dorsal spine }\end{array}$ & L4-L5, L5-S1 Retrolistesis & & & $\begin{array}{c}\text { Mild degenerative } \\
\text { signs in PIP and TMCs }\end{array}$ & $\begin{array}{l}\text { Synovial fluid in talo- } \\
\text { navicular and tarsal joints }\end{array}$ \\
\hline Axial/joint & $\begin{array}{l}\text { Degenerative axial } \\
\text { and joint signs }\end{array}$ & & C5-C6-C7 Protrusions & & & & \\
\hline Diagnosis & $\begin{array}{l}\text { OA } \\
\text { CPPD }\end{array}$ & $\mathrm{OA}$ & $\begin{array}{c}\text { OA } \\
\text { Discopathy }\end{array}$ & PsA & $\begin{array}{l}\text { Fibromyalgia } \\
\text { Chronic fatigue }\end{array}$ & $\mathrm{OA}$ & Resolved foot arthritis \\
\hline
\end{tabular}


Conclusions: Anti-DFS70 is a valuable biomarker, with a very low prevalence in $S A D$, which gives it a role as a negative predictive marker of developing SAD when it is appears alone. Its detection in serum with a dense fine speckled pattern ANA (IFI) should be part of the protocol of the immunology laboratory. It is a cost-effective determination, as demonstrated in a recent study, by avoiding the costs associated with the follow-up of these patients. In our case, its finding allowed us to reassure the patient and avoid the accomplishment of further complementary tests, as well as an unnecessary monitoring.

Disclosure of Interest: None declared

DOI: 10.1136/annrheumdis-2017-eular.3410

\section{AB1017 THE DEFEAT OF THE HIP JOINT IN ANKYLOSING SPONDYLITIS BY MAGNETIC RESONANCE IMAGING}

E. Agafonova ${ }^{1,1}$, T. Dubinina, A. Dyomina, O. Rumiantceva, D. Rumiantceva, M. Podryadnova, A. Starkova, S. Krasnenko, M. Urumova, S. Erdes. Laboratory seronegative spondyloarthritis, Nasonova Research Institute of Rheumatology, Moscow, Russian Federation

Background: According to the carried out epidemiological studies in Russia of patients with ankylosing spondylitis (AS) defeat of the hip joints was impairment in $46 \%$ of cases, but was the reason for the replacement in $7 \%$ of cases. $i$

Objectives: To compare the clinical manifestations of hip arthritis (coxitis) with the results of magnetic resonance imaging (MRI) of the hip joints $(\mathrm{HJ})$ in patients with ankylosing spondylitis (AS).

Methods: Examined 117 patients (mean age $31,7 \pm 12.7$ y meeting modified $N-Y$ criteria), with complaints of pain in the hip joints. The average age of onset of disease was $26.3 \pm 20.3$ years, HLA-B27 identified in $93 \%$ of patients. The median duration of AS - 57 [2-384] months. BASDAI 5,7 $\pm 3,1$. Diagnosis of hip septic arthritis were made based on clinical signs - the presence of pain in hips and/or restriction of movements in $\mathrm{HJ}$ at the time of patient admission to the clinic. In addition to clinical and radiographic examination all patients were performed MRI modes T1 and STIR.

Results: The Median duration of clinical manifestations of coxitis by the time of the study was 60 months. [25\%; $75 \%$ ], evaluation of pain in $\mathrm{HJ}$ for numeric rating scaler (NRS) - 4 [2; 8]. According to MRI identified the following inflammatory changes (IC): synovitis-71 (83\%) patients, bone marrow edema (BME)- $44(31,6 \%)$ patients (BME acetabulum $36 \%$, BME heads $63 \%$ ), a combination of synovitis and BME were 7 patients $(9 \%)$. Depending on radiological stage (estimated by BASRI hip), patients were divided into two groups (table 1).

Results:

\begin{tabular}{|c|c|c|c|}
\hline Parameters & $\begin{array}{c}\text { Group (1) } \\
\text { BASRI hip 0-I }(n=48)\end{array}$ & $\begin{array}{c}\text { Group (2) } \\
\text { BASRI hip II-IV (n=60) }\end{array}$ & $\mathrm{P}$ \\
\hline Gender (w/m), n & $20 / 28$ & $33 / 36$ & $0,04^{*}$ \\
\hline AS duration,mo, Me $[25 \%, 75 \%$ o] & $43[19 ; 80]$ & $102[24 ; 120]$ & $0,006^{*}$ \\
\hline BASDAI, Me [25\%, 75\%。] & $4,1[2,6 ; 5,5]$ & $5,6[4,2 ; 6,7]$ & $0,003^{*}$ \\
\hline BASFI, Me $[25 \%, 75 \%]$ & $2,8[2,0 ; 3,8]$ & $3,3[2,0 ; 5,4]$ & $0,2^{*}$ \\
\hline HLA-B27, n (\%) & $96(91 \%)$ & $84(91 \%)$ & $0,7^{\star}$ \\
\hline ASDAS (CRP) Me $[25 \%, 75 \%]$ & $2,8[2,0 ; 3,8]$ & $3,5[2,6 ; 3,8]$ & $0,002^{*}$ \\
\hline $\mathrm{ESR}, \mathrm{mm} / \mathrm{h}, \mathrm{Me}[25 \%, 75 \%]$ & $10[5 ; 25]$ & $25[8 ; 35]$ & $0,001^{*}$ \\
\hline $\mathrm{CRP}, \mathrm{mg} / \mathrm{mL}$, Me $[25 \%, 75 \% \mathrm{o}]$ & $10,5[3,8 ; 28,5]$ & $23,0[4,9 ; 43,5]$ & $0,06^{*}$ \\
\hline NRS, Me $[25 \%, 75 \%$ ] & $5[3 ; 6]$ & $6[4 ; 7]$ & $0,01^{*}$ \\
\hline MRI Synovitis n (\%) & $44(92 \%)$ & $27(45 \%)$ & $0,003^{*}$ \\
\hline Osteitis n (\%) & $6(12,5 \%)$ & $38(64 \%)$ & $0,0001^{*}$ \\
\hline
\end{tabular}

Conclusions: MRI allows to clarify the cause of the pain and limitations of movement in $\mathrm{HJ}$ with AS, determine the patient has inflammatory changes, including in the absence of radiographic changes in these joints. Patients with severe radiological change (BASRI II-IV), have a greater duration of the disease, severe functional abnormalities in the BASFI index. With increasing radiological stage (BASRI hip II-IV) increased the detection rate of osteitis by MRI. Further research to clarify the relationship of clinical manifestations of coxitis (pain level) from MRI data.

Disclosure of Interest: None declared

DOI: 10.1136/annrheumdis-2017-eular.4985

\section{AB1018 DETECTION OF ANTI-DFS70 ANTIBODIES BY INDIRECT IMMUNOFLUORESCENCE (IIF) ON NOVEL HEP-2/DFS70-KO SUBSTRATE FOR DISCRIMINATING ANTINUCLEAR ANTIBODIES (ANA) - POSITIVE HEALTHY INDIVIDUALS (HI) AND PATIENTS WITH SYSTEMIC LUPUS ERYTHEMATOSUS (SLE)}

E. Aleksandrova, Z. Verizhnikova, A. Novikov, T. Panafidina, T. Popkova. V.A. Nasonova Research Institute of Rheumatology, Moscow, Russian Federation

Background: Autoantibodies against intracellular antigens are a serological hallmark of ANA-associated systemic autoimmune rheumatic diseases (AARD) such as SLE. IIF on HEp-2 cells for ANA remains the "gold standard" but it has very low positive predictive value. Up to $20 \%$ of serum samples from $\mathrm{HI}$ have been reported to have a positive ANA IIF test, the majority of them due to the presence of anti-dense fine speckled 70 (anti-DFS70) antibodies. Monospecific
anti-DFS70 antibodies represent a biomarker that can be used to discriminate AARD patients (pts) from HI in ANA IIF positive subjects. Recognition of the DFS70 ANA IIF pattern can be challenging. The DFS-KO Hep-2 cells inhibit anti-DFS70 antibodies reactions, providing clear differentiation of the DFS pattern from classical ANA patterns.

Objectives: To evaluate the utility of a novel HEp-2/DFS70-KO IIF substrate for the detection of anti-DFS70 antibodies in HI and SLE pts.

Methods: We studied $45 \mathrm{HI}$ (36 F/9 M; age 50.4 [24.0-72.0] years, median [interquartile range $25-75 \%$ ]) and 12 pts with SLE (ACR criteria, 1997) (10 F/2M, age 38.9 [17.0-65.0] years; disease duration 100.3 [4.0-432.0] months; SLEDAI $2 \mathrm{~K}$ score 11.7 [2-30]; SLICC damage index score 1.28 [0-4]). Serum samples were tested for classical ANA and anti-DFS70 antibodies by IIF technique with a mixture of standard HEp-2 cells and DFS70-KO HEp-2 cells ("Trinity Biotech", Bray, Ireland) as a substrate. Fluorescence titers $\geq 1$ : 160 were considered as positive for ANA patterns.

Results: ANA were present in $7 / 45(15.6 \%)$ of $\mathrm{HI}$ and in $12 / 12(100 \%)$ of SLE pts. All SLE pts and $3 / 45(6.7 \%)$ of HI showed classic ANA patterns (homogeneous, speckled, and mixed) in the absence of DFS70 pattern. $4 / 45(8.9 \%)$ of $\mathrm{HI}$ had classic ANA negative/anti-DFS70 antibodies positive IIF results. Isolated anti-DFS70 antibodies were found in $57 \%$ of ANA IIF positive HI. Among HI classic ANA and anti-DFS70 antibodies were detected in the low- to medium-titer range (1:1601:320). The frequency of anti-DFS70 antibodies did not correlated with age. Conclusions: The detection of isolated anti-DFS70 antibodies may be regarded as an exclusion criterion for the diagnosis of SLE. The testing for anti-DFS70 antibodies in a single step by HEp-2/DFS70-KO IIF method should be included into a modified ANA diagnostic algorithm. Additional investigations are required to evaluate the clinical relevance of anti-DFS70 autoantibodies.

Disclosure of Interest: None declared

DOI: 10.1136/annrheumdis-2017-eular.4008

\section{AB1019 ASSOCIATION OF INFLAMMATORY DISEASES - A CURRENT TOPIC FOR THE PRACTITIONER}

A. Cardoneanu ${ }^{1,2}$, A. Burlui ${ }^{1,2}$, C. Cijevschi Prelipcean ${ }^{3}$, E. Rezus ${ }^{1,2}$

${ }^{1}$ Rheumatology, University of Medicine and Pharmacy "Gr.T.Popa";

${ }^{2}$ Rheumatology Clinic, Rehabilitation Hospital; ${ }^{3}$ Gastroenterology, University of Medicine and Pharmacy "Gr.T.Popa", iasi, Romania

Background: Autoimmune, infectious, traumatic or neoplastic inflammation represents a warning for the practitioner. Numerous clinical specialties face daily with the presence of inflammation. The efforts of medical staff aim to establish the pathogenesis, the expansion and to find the most effective ways of treatment. Objectives: Our study objective is to highlight the correlations between Spondylarthropathies $(\mathrm{SpA})$ and intestinal manifestations, the link between the antigen HLA B27 and joint and intestinal inflammatory changes and also the relationship between the presence of sacroilitis and bowel disorders.

Methods: The study included 42 patients ( 28 men, 14 women). Of the 42 patients, 31 were diagnosed with ankylosing spondylitis (AS) (according to modified New York criteria), 8 with psoriatic arthritis (PSA) (using CASPAR diagnosis criteria) and 3 patients had had reactive arthritis (ReA) (according to ASAS criteria). All subjects enrolled in the study were screened for the presence of the antigen HLA-B27. Sacroiliitis was highlighted through pelvis X-ray centered on the SI joints. All patients diagnosed with AS presented radiological sacroiliitis, only 5 cases in the group of PsA and 1 patient diagnosed with ReA. To investigate the presence of intestinal inflammation, a colonoscopy with biopsy was performed to all subjects included in the study. Among patients with AS, 5 of them had inflammatory changes suggestive of Crohn's disease (CD) and 2 for ulcerative colitis (UC). Subclinical intestinal inflammation was evidenced in 15 cases: 12 of SA group and 3 of PsA group. We also highlighted 7 cases of irritable bowel syndrome: 1 patient with PsA and 6 patients with SA.

Results: After the statistical analysis of the collected data, the following statistically significant correlations were found $(p<0.05)$ : radiological sacroilitis correlated with AS and PsA; the antigen HLA-B27 is in close relation with all 3 forms of spondylarthritis; subclinical intestinal inflammation was positively correlated with AS and PsA. No associations were found between the presence of intestinal inflammation and sacroilititis.

Conclusions: This study points the link between intestinal and joint inflammation, primarily due to a common pathogenic mechanisms. A careful monitoring and a close collaboration between gastroenterologists and rheumatologists contributes to an optimal management of these patients.

References:

[1] Baeten D, de Keyser F, Mielants H, Veys EM. Ankylosing spondylitis and bowel disease. Best Pract Res Clin Rheumatol Sep 2002;16(4):537-549.

[2] Salmi M, Jalkanen S. Human leukocyte subpopulations from inflamed gut bind to joint vasculature using distinct sets of adhesion molecules. J Immunol 2001;166:4650-4657.

[3] May E, Marker-Hermann E, Wittig BM, Zeitz M, Meyer zum Buschenfelde $\mathrm{KH}$, Duchmann R. Identical T-cell expansions in the colon mucosa and the synovium of a patient with enterogenic spondyloarthropathy. Gastroenterology 2000;119:1745-1755.

[4] Peeters $H$, vanderCruyssen $B$, vander Cruyssen $B$, Mielants $H$, de Vlam K, Vermeire $\mathrm{S}$, et al. Clinical and genetic factors associated with sacroiliitis in Crohn's disease. J Gastroenterol Hepatol Jan 2008;23(1):132-137. 